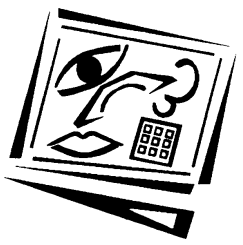

\title{
Role play in blended learning: A case study exploring the impact of story and other elements
}

\author{
Mary Dracup \\ Deakin University
}

Role play is an increasingly popular technique in tertiary education, being student centred, constructivist and suitable for a range of subject areas. The choice of formats is wide open, with options ranging from the traditional face to face performance through to multi-user online computer games. Some teachers prefer to take advantage of features of both online and face to face formats and offer a blended form. This case study describes an innovative blended role play in which the online component plays a small but important part. The findings show that decisions on not only how to make the best use of technology but also how to design and facilitate a role play can have a profound effect on the creation of an engaging first-person story from which powerful learning can be drawn-in this case, learning outcomes including deep insights into strengths and weaknesses of participants' personal change management styles.

\section{Introduction}

The scope for stories and role play in producing effective learning in online and blended modes has been of interest to me for some time in my work in the Institute of Teaching and Learning at Deakin University. I undertook the case study described in this paper as part of my Masters research in the area. My initial goal was to examine the impact of the story based aspects of an innovative blended online and face to face role play on the participants' learning. I found that certain qualities of the performance mode and style of facilitation, as well as choices in the way setting, plot and characters were managed, were very important not only in driving the development of the role play, but also in intensifying participants' engagement in and enjoyment of the activity, and stimulating them to form personally meaningful and lasting conclusions. In particular, I found that the ways in which confronting and/or unsettling dimensions were managed by the facilitator and respondents had a significant influence on the learning students took from the unit.

Role plays are increasingly popular in tertiary as well as vocational education in Australia and elsewhere (Bolton \& Heathcote, 1999; O'Toole, 2002; van Ments, 1999). They have been found to produce deep level learning outcomes that resonate for a long time (Bolton \& Heathcote, 1999; Raphael \& O'Mara, 2002; O'Toole, 2002; van Ments, 1999). What is more, students tend to enjoy the technique (Raphael \& O'Mara, 2002; Simons, 2002; Sinclair, 2002; van Ments, 1999); and teachers tend to find it exciting and rewarding (Bolton \& Heathcote, 1999). To take part in a role play, whether in face to face or some kind of online form, is to enter into an imaginary world and explore possibilities there with other players. In doing so, players take a character part in developing a dramatic story, with a sense of freedom and play, to create an experience from which meaning can be drawn. 
The story is a natural form of communication that not only allows people to pass on information but also engage their audience's emotions. Egan (1997, 33-36) outlines evidence from across cultures that the story form arose as a 'cognitive tool' soon after humans developed the ability for language. Stories are ubiquitous in our popular media and daily lives: story elements can be recognised in not only fairy stories, myth, television dramas and news, but also gossip, advertisements, anecdotes, songs and jokes (Nell, 2002). They are also evident in more serious matters such as history (White, 1980), scientific theory (Harre, 1990), economics (McClusky, 1990) and jury decisionmaking (Graesser, Olde \& Klettke, 2002). In my experience in the tertiary education sector over the past 10 years I have seen abundant use of stories in the form of anecdotes, examples and case studies to support, illustrate and enliven abstract concepts, but, as McEwan and Egan (1995, xii) argue, their educative function has tended to be marginalised to mere 'entertainment value' in 'an age that values nonnarrative discourse as a measure of sophistication in rationality'.

In research into online teaching and learning in recent years, however, there has been increasing interest in learning and teaching techniques in which the development of a story provides a central element and driving force for the learning experience, such as online role play and computer games. The interest has been prompted by several factors, including the pedagogical shift towards constructivist learning and teaching techniques; the desire to take advantage of the affordances of online technologies; and teachers' efforts to find ways to engage 'Generation $Y^{\prime}$ 'students with their apparent preference for playful, collaborative, active and technology based learning and teaching techniques (Prensky, 2001, 2006; Carroll, Anderson \& Cameron, 2006).

\section{Story based learning and teaching techniques}

Literary theory defines the story concept and demonstrates how the important story elements of character, plot and setting work to engage readers, and increase their enjoyment and understanding at the same time. A 'story' is:

... in everyday sense, any narrative or tale recounting a series of events ... in modern narratology ... the sequence of imagined events that we reconstruct from the actual arrangement of a narrative (or dramatic) plot (Baldick, 1990, 211).

The narratological definition acknowledges that each audience member will construct his or her own interpretation of a tale, and this is ultimately the 'story' for him or her regardless of what the author might have intended. It also takes into account that the sequence of events in a story form is arranged as a narrated or dramatic plot. This therefore excludes from the definition of 'story' those forms of expression that merely list, describe or lecture. The idea of 'plot' dates from Aristotle's Poetics in 350 BC, its requirements being a central subject; a beginning, middle and end; characters endowed with qualities that dictate their actions and the progression of events; and a necessary connection between one event and another such that a sense of coherence and meaning is formed (Halliwell, 1995). Ryan (2001), drawing on more recent developments in literary theory as she explores the phenomenon of the reader's imaginative 'immersion' in virtual worlds, also acknowledges the basic importance to the construction of a story of setting. Thus, I have aligned my definition of story with Ryan's $(2001,15)$ argument that it is the three elements of plot, character and setting that make up the basic story components. 
Just how the process of engaging in and making meaning from stories works, and how it can be used most effectively to entertain, educate, and more insidiously persuade has been the subject of considerable conjecture and research since ancient times. Aristotle's principles for the creation of engaging drama still resonate among writers in literary theory, including those concerned with how the dramatic story form works in interactive media (e.g. Laurel, 1991; Ryan, 2001). The classic psychological explanation for how readers and audiences become engaged with stories is Samuel Taylor Coleridge's $(1817 / 2004)$ notion of 'willing suspension of disbelief', in which readers/audiences willingly pretend the action they are witnessing in a story is real so they can have the thrill of experiencing the characters' emotional responses as their own, while knowing the action is not real saves them from a true level of pain and fear.

Egan (1997, 44-65) argues that humans have a natural tendency to make images of and attach emotional responses to contexts and characters that we hear or read about. He argues that having made this personal association, the story about what these imaginary characters do or what happens to them in the imagined space becomes in an important sense our own. Misson and Morgan (2006) argue that a reader's or audience's knowledge of culturally-based story genres (eg the quest, detective story, or romance) are very important to their ability to suspend disbelief, and also enjoy the experience, as they provide a predictable, satisfying format for what will happen. Misson and Morgan (2006) demonstrate that manipulating elements in a story so that generic expectations are toyed with thus can have a particularly strong emotional and educational effect. Exploring these features of the story form reveals why stories lend themselves to use in education. Stories can offer the opportunity not only to expand an audience's experience of the world and entertain them, but to extend and question their attitudes and values.

\section{Role play as participating in a story}

Even before most of Generation Y was born (between about 1980 and 1994), educational theorists such as Dewey (Archambault, 1964), Malone (1981) and Vygotsky (1978) were highlighting the value of active, playful and collaborative styles of learning. Learning and teaching techniques that use a story in which the student can become directly involved in the action and influence outcomes, such as multi-user computer games and role plays, offer rich opportunities for the exercise of such styles. They may also offer opportunities for experiential learning (Kolb 1984): computer game and role play experts (e.g. Gee, 2003; Bolton \& Heathcote, 1999) argue that these forms can combine a cognitively realistic synthesis of the most important aspects of real situations, with the added advantage of being able to engage students deeply, meaningfully and enjoyably in the activity.

The role play structure in face to face as well as online modes contains considerable space for students to develop both character and actions according to their experience and imagination. Thus, it can enable students to explore values and issues that are highly relevant to their own needs and culture, in their own language, and with stimulation and instant feedback from their peers (Cahill, 2002). Another advantage of role play is that, unlike most computer games, they do not rely on rich graphics and complicated programming to create context and interactivity - the players collaborate 
in constructing the learning environment through their speech, actions or text communications.

Thus, they can be simple and inexpensive to set up, even in online format (Wills, Ip \& Bunnett, 2000). However, effective role plays do not just happen. It is argued (Ryan, 2001, 287; Murray, 1997, 151) that not everyone has a strong sense of how to create a good story, and participants' level of immersion in, and enjoyment of, the activity will be limited if some kind of dramatic framework is not established and maintained. It follows that the design of this framework and the skill with which it is maintained by facilitators are central to the role play's success as a learning and teaching technique.

Based on this review of the literature, I was keen to explore for myself what effects the underlying story form might have had on students' learning in a real role play that was performed at least partly online, in the contemporary tertiary education context; and whether it was possible therefore to propose generalisable theoretical principles relating to how best to manage story based learning and teaching techniques in tertiary education.

\section{The case study}

The case study within which I explored this question was a role play that took place in December 2006 as the central activity of a Deakin University MBA Change Management subject, with 51 student participants. It had two distinct components and performance modes. The first was a preliminary five-week online activity in which participants formed groups and performed group writing tasks designed to orientate them to the setting and subject matter. The second component was a traditional face to face role play that involved all students and occupied the first two days of a residential program. The role play was authored by John McWilliams and jointly facilitated by himself as unit chair and Ruby $\mathrm{Ma}$, a lecturer. It had been performed with minor variations by many student cohorts over a number of years. The role play contributed to John being awarded a Vice Chancellor's award in 2006.

\section{The online component}

The role play used the setting of two real organisations, namely the Victorian Country Fire Authority (CFA) and the Melbourne Fire Brigade (MFB). In the online component, participants used the Blackboard group sign-up feature to form groups of five, and then used their group's private asynchronous discussion space (and other communication media) to prepare a joint expression of interest to take roles within a management group (e.g. CFA Executive, MFB Command) or a staff group in a fire station (e.g. CFA North, MFB East). John then allocated the group roles and the two CEO roles, and the participants decided who would take which of the remaining positions in their group (e.g. HR manager, chief fire officer, station officer, etc). The participants' next task was to work in role with other groups within their organisation to research and jointly write a 2000 word report on current issues confronting their organisation as a whole (i.e. the MFB or CFA). Communication between the facilitators and both online organisations was made via the executive groups, which reinforced the hierarchical command structure. 


\section{The face to face component}

The face to face component of the role play began in the early afternoon soon after the participants arrived at the residential for this unit. Their first task was to present their organisation's joint report to the whole cohort. After a discussion in which John supplied more detail on the Victorian fire services context he set the next task, which was to work in more or less the same groups and roles to prepare a detailed options paper setting out strategies the CFA and MFB could use to meet the considerable challenges the organisations faced in the future. The groups worked in private syndicate rooms and used written questions delivered by 'liaison officers' to communicate across the CFA-MFB divide. Participants worked on this task over most of the next evening and morning.

The dramatic crisis came with the presentation of the organisations' options papers around the middle of the second day. In previous performances of the role play, John had taken the role of Fire Services Minister and at this point had announced a decision along the lines that the CFA and MFB were to merge, and that the two organisations were now required to work together to plan the shape and roles for the merged operation. However, this time John decided that, as many of the participants had been prepared for this intervention by previous students, he would do something different. He stayed out of role and simply made the judgement that while the CFA paper was acceptable, the MFB paper was less so, using vague criteria that had not been provided beforehand. From this point until a full debrief three days later, John intentionally violated the students' expectations not only of what might happen in the story plot that had been developing, but also of how the role play form itself should work.

After delivering his verdict on the CFA-MFB papers, many participants were clearly hurt and confused. A competitive environment had developed between the two groups and the fallout from John's judgement produced considerable discomfort for many participants (field notes 4/12, 1:20 pm). However, John did not make it clear whether the role play had ended or was just in recess, and set participants an unrelated poster-painting activity. The organisational groups called their own meetings to talk through their responses and make tentative plans for a possible next stage, but there was a hiatus of several hours in which many participants tried to resolve their feelings amongst themselves, unsure of whether it was time to shed their roles and 'move on'. John finally called the participants together to discuss the role play later in the afternoon, but he did not structure the discussion to debrief and help participants derole in the traditional way (e.g. as described by van Ments $(1999,133-52)$ ), and it was evident some participants were still trying to work out how they felt the following morning. John did finally confirm that the role play was finished that morning, but still delayed debriefing the participants in a traditional way. John later explained the rationale for his actions: he said leaving the participants to deal with what he knew would be an emotional, ambiguous group situation in their own way over an extended period allowed them to experience at first hand the kinds of personal emotional and managerial challenges that were often presented in the climate of confusion and poor communication that was typical of change situations. He argued that 'closing' the experience too early would have limited the personal reflective activity many of the participants undertook to sort out their feelings and learn about the nature of their own and other people's responses in these situations (interview 23/2/07). 
While participants were involved in other change management activities over the next few days, many reported continuing to explore their emotional responses to the role play and re-examining both groups' strategies and behaviours. However, John did conclude the residential with a conventional debriefing session that covered the role play and the other activities in which students had participated that week.

Participants were assessed for the unit on a pass / fail basis: if they completed the various tasks set before and during the residential they passed, but if they did not complete or take part in one or more tasks then they were obliged to write essays on change management as an alternative assessment. The participants' final task was to write individually a 2000-word 'reaction report' describing what they had learned from the unit and critiquing the techniques used, for submission five weeks after the residential.

\section{Method}

I used a case study research method because, as Yin (2003) argues, the method is particularly useful for investigating a phenomenon within its real life context. The case study format seeks to account for multiple variables of interest within a particular instance of experience, relying on triangulation of data from multiple sources to build theoretical insights (Yin, 2003; Freebody 2003). The method is particularly useful for educational research because it creates interactions between theory and particular cases that enable researchers to 'avoid the restrictive applications that come from, on the one hand, theorising "in a vacuum", or, on the other, appreciating the complexity and uniqueness of practice without presenting inspectable procedures for interrogation and explication' (Freebody, 2003, 81).

I used a grounded theory approach in my research design, data gathering and analysis (Strauss \& Corbin, 1998). Rather than setting out to test a preconceived theory, I started with broad research questions addressing the learning outcomes and overall effectiveness of the role play technique; the degree and nature of participants' engagement and enjoyment; the effects of each of the story elements of plot, character and setting underlying the technique; the effects of the online and face to face performance modes; and the effects of other non-story elements.

As far as was possible in the limited data collection time period, I sought to gather and analyse my data in cycles, using questions and comparisons to elucidate the findings and gather more data to answer further questions that arose and checking my interpretations with participants as I went. To enable closer scrutiny of the data, I coded data from the various sources according to its relevance to each of the research questions, and then copied and pasted the data into separate documents set up for each question. I used processes of both induction and deduction to look for patterns in the data in each document, and from these I proposed the conclusions outlined below.

A mixture of quantitative and qualitative data collection methods enabled me to capture the breadth of the participants' experience of the role play and also explore particular issues at depth. The methods included participant observation notes, a questionnaire, semi-structured interviews with John before, during and after the role play, a focus group interview, and analysis of both printouts of online discussions and 
student reaction papers. Ethical approval for the research project and methods was obtained from Deakin University's Human Research Ethics Committee.

Despite requesting all participants' consent to take part in the study by personal email twice before the start of the online component, only 27 (out of 51) returned signed forms, and unfortunately many of these did not arrive in time for me to take part in a discussion group for the online component. Members of two groups later provided their consent to my analysing the printouts of their discussions, but these contained little indication of the type and level of activity in the online component as both groups used mostly alternative means of communication (email lists and telephone conferences).

As both a participant and observer during the face to face component, I recorded discussions with those who had returned consents. This both supplied data and gave me a chance to make comparisons and check my interpretations. I was enrolled as a student in the subject and took an active but low key part in the role play, joining a group but also spending time in other groups. I took this role both to experience the effects of the role play at first hand and to better gain the confidence of the participants than would have been likely had I remained on the periphery. I was guided in my approach on models provided by Knobel and Lankshear (1999) and Gillham (2000). I took care to avoid influencing the action unduly or forming close relationships with participants that could either influence their responses or bias my own interpretations. However, as I recognised that some influence and bias was inevitable, I sought to be aware of my own assumptions and activities in the collection and interpretation of my observation data. I tried to balance my own experience of the role play with that of others by discussing the events with as large a number of participants as possible. I took field notes during the role play to record these discussions, the timing of events, my observations and my personal impressions.

The anonymous questionnaire was distributed on the evening of the second day, after the role play had finished. It was completed by 47 participants out of 51 . The aim of the questionnaire was to gather confidentially a wide range of data from a large sample of participants to identify trends across the whole group. The questions addressed each of the key research questions in broad terms, using both closed Likert scale questions and open questions.

The focus group interview was held in Melbourne in the middle of the week after the residential, to provide participants time to reflect on their experience but also capture their memory of the detail before it was forgotten. While all participants were invited and several dates and times were provided only two participants attended, due at least partly to geographical distances and work pressure in the weeks leading up to Christmas (particularly after a week away from work at the residential). Nevertheless, the interview, which was semi-structured, provided the opportunity to explore significant issues that had arisen from the questionnaire data at depth, and to check my participant observation interpretations.

Another major source of data was the consenting participants' 2000-word reaction papers, submitted a few weeks after the residential. In these, participants were asked to express their 'reactions to and learning from the unit', and invited to criticise or 
praise the techniques that had been used. They provided a breadth of opinion as well as some deep insights into what and how the participants learned. However, in my analysis of this data I took into account that as these papers were submitted to John as a hurdle requirement to pass the unit, the opinions expressed might not have been entirely frank and genuine.

\section{Findings and discussion}

The trends across all sources of data indicated that participants thought the role play technique not only had been an effective and enjoyable means of learning important aspects of how to manage change better, but that what they had learned was likely to be transferred to their real lives. A small number said the experience had 'changed their lives'. While a number of factors were found to be important to the success of the technique, a significant portion of its success can be attributed to aspects of the role play's participative story format.

\section{Learning outcomes and overall impressions}

The questionnaire responses indicated $80 \%$ of participants agreed or strongly agreed (on a 5-point Likert scale) that 'As a result of taking part in the role play I am likely to manage change better in my real life'. However, nine of the 21 comments to this question were ambivalent or even negative, such as: 'I am still waiting for the learning', 'Not challenging enough to get strong learnings about change' and 'Didn't work. Waste of time'. John proposed only the broadest learning outcomes for the role play: 'This week, the aim is to learn about the best ways to help people through change' (field notes 3/12 2:20 pm), explaining later (interview 23/2/07) that this was because different people would learn different things, depending on their readiness to learn from the experience they would have; and also because the understanding necessary to manage change well was tacit, difficult to articulate and beyond any one structural system: 'really good change management is empathic, insightful ... you need to understand the dynamics of change so that your instincts are aligned with what's required'.

When asked about his reaction to the negative comments, he said it was common for participants who initially reacted negatively to the role play to tell him that after weeks, months or years they eventually realised it had helped them to learn something important. (It should be noted that the questionnaire was delivered at the end of day two, before the week's final debriefing.) The learning outcomes many participants identified in their reaction papers and the focus group included a range of insights into how they personally might better manage a range of personality types through an unpredictable and frequently irrational process. Many participants commented that the experience had highlighted their personal strengths and weaknesses in the 'soft skills' involved. For example (student participants' names have been replaced with pseudonyms):

I now understand that providing the vision alone is unlikely to be effective. At the core

of any method of managing change that I choose, needs to be a deep consideration of the people affected, why they might resist change, and how this resistance can be lowered. This needs to be combined with a very well developed and maintained communication policy (Sol's reaction paper). 
... it is important to establish common aims and objectives to help people stay focused, particularly in terms of increased uncertainty ... the Fire case showed that without an agreed direction for an organisation, things can seem quite chaotic and as if little progress is being made, as no-one really knows where they are supposed to be heading (Lionel's reaction paper).

Other participants identified strategies they intended to pursue (and in some cases had already started to implement), such as to show leadership even when they don't feel strong (Jane, focus group), to keep communicating even when there is no new information to give (Felix, focus group), to keep asking questions and provide timely communication and feedback (Corinne's reaction paper) and to allow people more time and scope to adjust in their own way (Kerry's reaction paper).

\section{Engagement in and enjoyment of the role play}

The questionnaire results indicated that $88 \%$ agreed or strongly agreed that they 'enjoyed taking part' in the role play; $77 \%$ agreed or strongly agreed that they 'felt more motivated to learn about the subject than [they normally felt] when learning from lectures/tutorials/study guide'; and 75\% agreed or strongly agreed that they 'engaged with the subject at a deeper level than [they normally achieved] with lectures/tutorials/study guide'. Some comments to these questions were:

You became involved, you had a more emotional attachment to outcomes. You were able to observe 'real' reactions.

As part of a group, I had an increased sense of responsibility to perform.

More motivated—created a sense of purpose—accelerated group dynamics

But also:

I was frustrated and bored. I really struggled to understand any new learning. Some was achieved through a personal debrief.

These results were borne out in my observation that most participants worked on their role play tasks late into the night (field notes 3/12, 9:40 pm). When I explored the source of participants' motivation and engagement in the focus group, both participants claimed that their peers were typically high achievers who were likely to engage readily in any learning activity, but that the element of competition between the CFA and MFB groups was a key motivator (this is discussed further below). However, as indicated in the fourth comment above, not all participants were engaged deeply at all times: Felix admitted in the focus group that he was 'bored, absolutely bored' at one point when his group had finished its work and, being in low responsibility roles, had nothing to do for some time.

\section{The story elements: Setting}

Setting the role play in the Victorian Country Fire Authority and Melbourne Metropolitan Fire Brigade context proved a timely choice for a residential situated in drought stricken rural Victoria during a December in which daily news reports brought footage of thousands of acres of burning bushland. According to Bolton and Heathcote (1999), for a role play to be successful it must be interesting, realistic, 
relevant and challenging, otherwise participants are less likely to suspend their disbelief, engage deeply in the activity and form parallels between the activity and real life. Questionnaire responses indicated the following percentages of participants agreed or strongly agreed that each of these qualities were present in the role play: realism $(68 \%)$, relevance $(66 \%)$, interestingness $(92 \%)$ and challenge $(72 \%)$.

Considerable efforts were made to ensure participants were familiar with the structure, culture, tasks and issues in the CFA and MFB. They were obliged to research current issues facing these organisations in the online activity run over several weeks before the residential started, and were given $\mathrm{CD}$ and web based material to help them understand these organisational settings. Some participants contacted the actual organisations and their union for more detailed and personalised information. When the residential opened, large CFA posters with fire fighting action pictures were set up, two CFA members were on hand and two fire trucks were on display. Participants were given an activity to familiarise themselves with the trucks and equipment, and the CFA representatives stayed on to answer questions. Such was the participants' understanding and acceptance of their authentic setting and roles that the two real CFA representatives commented that the conclusions, recommendations and personal styles the role playing CFA and MFB executives expressed in their presentations were extremely similar to those expressed by the real executives with whom they worked (field notes 3/12, 4:50pm).

Bolton and Heathcote $(1999,45)$ argue that the setting for a role play should create a 'thin screen'. This allows participants to feel safe in the knowledge they are acting in a make believe world, in which it doesn't really matter if they make mistakes; and at the same time enables them to make connections between what they are experiencing and what life is really like. Several reaction paper and focus group comments indicate the setting for this role play was successful in this respect, e.g.:

Soon all the students would become entrenched in a cultural experience that would become [so] reflective of a real life situation it was frightening (Ernest's reaction paper).

As a member of the MFB you felt totally immersed in the culture and dynamics of the organisation. I believe that this was an extremely powerful way to show the group indirectly the impacts of change and in particular the different human reactions to change. You could look around the room at any given time and read a host of different expressions on people's faces and what that might mean for how they were coping with the change process (Corinne's reaction paper).

\section{The story elements: Plot}

The early events of the role play followed a classic dramatic structure involving an exposition, a steady building of suspense, complications and conflict, and a climax. Participants quickly adopted a team based 'quest' genre, setting themselves up as adversarial groups in pursuit of a common goal. Suspense was generated as participants wondered what 'twists' John might introduce. Complications and conflict arose as the organisations sought information from one another and frequently were thwarted. However, the climax, created by what many perceived as John's unfair judgement of the groups' performance (field notes 4/12, 5:30pm, Garry's and Harry's 
reaction papers) and John's delay in providing closure, did not produce a satisfying resolution, but instead widespread emotional and intellectual confusion. Reaction paper and focus group comments indicate that while the lack of immediate resolution produced discomfort for many, it proved very useful from the point of view of prompting intense individual and group reflection on what could be learnt from the experience, for example:

This sparked a huge amount in internal questioning. There were people who were emotionally hurt, there were small groups endlessly discussing where we missed the point, and they were blaming the slightly ineffective organisational structure. It was very interesting to see how different people could let it go and move on and others who continuously look back and analyse it. After a few hours most of the group had resolved the issues in their own minds and come up with the following conclusions ... (Harry's reaction paper).
The discomfort of the desert continued the next morning when we sat in the room trying to decide whether the exercise was over. Some people were ready to move on and others weren't. This highlighted to me that people respond differently to change. Some people wanted to hang on to the exercise because it had structure. Also, I imagine it made some people uncomfortable to not have received any marks on the work done so far; to abandon it would have seemed to them to have wasted a lot of time. I thought that the exercise had served its purpose, the output to me wasn't actually important. I think that any half decent group of MBA students should be able to research, analyse and present information, which we did. But that wasn't the point of the exercise it was just a method to get us to interact, to form our tribes and to see how quickly divisions, alliances and stories can form (Jane's reaction paper).

The let down and confusion that participants experienced was not accidental, but fundamental to this role play's design. John described the role play (in the 4/5/06 interview) as:

\begin{abstract}
creating a world where their expectations are going to be disconfirmed ... we need to soften people up so they don't cling to a simple format of change ... in the first few tasks we help them develop a sense of identity with their group, then we put them under stress to create the dynamics of resistance to change ... they live the experience of finding themselves in a situation where the ground is shifting, where there is a real level of anxiety ... over the next few days they have to make sense of the dynamics that develop.
\end{abstract}

The effect of the way the plot to this role play developed, inviting participants' engagement but then depriving them of the emotional satisfaction they expect in order to force them to review their expectations, behaviour and values, bears out Misson and Morgan's (2006) argument that genre is deeply involved in building people's expectations and hence their emotional and intellectual engagement in a story; and that manipulating generic elements can produce powerful insights into accepted behaviours, values and stereotypes.

\title{
The story elements: Character
}

By means of signing up for particular groups and then writing a joint expression of interest, participants had some control over whether they were in an executive or command group, or one of three station groups that were set up for each organisation. 
Roughly half of the participants had some kind of management role, making decisions on how the vision and management plan for their organisation should change; and the remainder were station staff, their task simply to contribute information for their organisation's options paper. The allocation of roles therefore had significant bearing on participants' point of view and level of activity, and this is reflected in the questionnaire response that only $60 \%$ strongly agreed or agreed that 'I could influence what happened next in the role play'. However, several commented that their powerless position helped them better appreciate the challenges of 'influencing up'. Responses to other questions indicate that adopting a role in the role play enhanced most participants learning in some way: $89 \%$ agreed or strongly agreed that 'participating in the role play helped me learn more about my own and others' motivations, actions and reactions'; and 77\% agreed or strongly agreed that 'acting in role that was different to my real life role gave me a different perspective'.

No instructions were given on the types of characteristics participants should portray. This meant that while it was evident that participants quickly identified as members of separate groups, and the executives clearly took on a mantle of responsibility for outcomes, the main characteristics that came into play were the individuals' own, rather than those of a character role 'overlay'. Both focus group participants commented that this strategy was effective. Jane argued that having participants act themselves in the situation created a more powerful and memorable learning experience than they would have had, had they been able to 'hide behind' a more fully developed character role. She added that it was not necessary to simulate personalities as 'with 52 people in that room I think you get the full range'. Felix argued that to have set up artificial roles would have tended to make the activity task- and issues-based, rather than an exercise in experiencing and dealing with people's genuine reactions, and 'change management is not task-oriented'. These comments support Bolton and Heathcote's $(1999,45)$ argument that the advantage of participants having only a thin fiction of a character role is that it contributes to the 'thin screen' effect.

Another important aspect of the character role that numerous reaction paper and questionnaire comments noted is that participants quickly identified as members of either the CFA or MFB group, and become caught up in the fairly fierce level of competition that developed between the two simulated organisations. John said competition arose between the groups every time he ran the role play: 'Competition happens naturally, you can't prevent it' (interview 6/12). Competition has long been recognised as a means of inreasing engagement in both playful and learning activities, an effect it clearly produced in this role play.

\section{Other important factors: The blended online and face to face mode}

\section{The online component}

The main purpose of the online activity was to prepare participants for the face to face component, in helping them orientate themselves to the setting and start to develop their group/character identity (John interviews $4 / 5 / 06,23 / 2 / 07$ ). To this extent, it was successful: $87 \%$ of questionnaire respondents who took part in the online activity agreed or strongly agreed that 'I would have felt less prepared for [the face to face component of] the role play had I not taken part in the online activity'; $81 \%$ agreed or strongly agreed the activity 'helped me get to know the other participants'; and 73\% 
agreed or strongly agreed the activity 'helped me understand and identify with the CFA/MFB organisational setting and culture'.

However, John reported (interview 23/2/07) that only six of the 10 groups completed the assigned task for this activity; and both of the focus group participants admitted doing only just enough work to comply with the hurdle task requirements. According to questionnaire and focus group comments, participants' engagement in the activity was limited by access difficulties due to the Blackboard system upgrade occurring during the activity, slowness of the system, lack of familiarity with the software, lack of time due to other commitments, and poor communication from John about what was expected. According to the literature (e.g. Wills \& Ip 2002, Moderator's checklist), online role plays require significant teacher support to help establish roles, clarify tasks and responsibilities, support acquisition of technical skills, set up a trusting environment, etc. While the online component was evidently successful in achieving its purpose, these responses indicate it may have been even more effective without the technical problems and with more teacher support and communication.

The face-to-face component

The residential format allowed the role play to run continuously over two days with very few external distractions. Questionnaire respondents provided a mean score of $4.33 / 5$ for the importance of the residential format as a factor in their learning. Participants' comments (e.g. field notes 4/12, 1:20pm, Jane's focus group interview) indicated that the intensive focus on the activity the residential format afforded enabled them to become deeply involved in the tasks and observe the physical group dynamics that resulted from this process, take the necessary time to reflect on what they were learning, share their insights with their peers, and support one other.

\section{Other important factors: the role of the facilitators}

Bolton and Heathcote (1999) and van Ments (1999) argue that role plays require skilful facilitation, in particular of reflection/debriefing sessions, to ensure firstly that students are not harmed by their experience, and secondly that they are able to form useful meanings from their experience. When participants were asked in the questionnaire to score the effectiveness of the role play's facilitation and reflection and debriefing sessions, they provided a mean score of 3.13 and $3.49 / 5$ respectively. However, these numbers do not reveal the range of opinion on this subject, e.g.:

I felt that the remainder of Monday afternoon [ie the post-role play discussion session] and Tuesday were almost completely wasted, and I truly feel that this is the point at which people became frustrated. Personally I remained indifferent, defensive barriers holding up well. I still don't understand what the Monday afternoon ... session was all about ... The final debrief session was great and I felt that we would have benefited from more of these (Sol's reaction paper).

You can change people by confusing them, or by letting them think. They say that structure liberates, but so too can chaos (Ivan's reaction paper).

John said (interview 4/5/06) that he purposely avoided managing the participants' experience too closely: 
The best experiences are minimally structured so the dynamics are created by the group reacting to the situation ... The sort of experience you need to have to be good at dealing with ambiguity is the experience of dealing with ambiguity.

However, he added that the activity did contain both safeguards and closure. Safeguards included that either he or Ruby were constantly monitoring participants' responses and frequently provided support to groups and individuals as it was called for. Also, he said he was prepared to introduce changes of direction in the activity if he sensed it was necessary to reduce pressure. He said (interview 23/2/07) that he aimed to ensure participants did not leave the residential with unresolved emotions, and to this end set aside the final morning for a thorough debrief in a traditional style.

\section{Other important factors: Participants' maturity and level of self reliance}

Unfortunately, the participants' ages did not allow conclusions to be drawn about the effectiveness of the role play for 'Generation $Y$ ' students, as only two participants were aged under 30. Most participants (68\%) were aged between 30 and 40 and the remaining $28 \%$ were over 40 . There were no significant differences between any of the age groups' responses to the questionnaire questions. When asked whether they thought the role play would be more or less effective with younger or older age groups, the focus group participants echoed John's opinion (interview 23/2/07) that having sufficient 'personal maturity', 'life experience' and 'self insight' were more important factors than age. The case study did not collect data on personal characteristics such as these, but as these qualities tend to increase with age it may be that this role play technique would not work well with younger students.

\section{Conclusion}

The effectiveness of the role play technique described above as a means of helping students learn important aspects of how to manage change can be attributed to a range of factors. The blending of online and face to face modes contributed to a successful outcome, and the way the role play was facilitated and debriefed was particularly significant. However, the underlying story of being a member of the CFA or MFB in a time of change drove this activity and provided the emotional and intellectual basis for the students' learning about change management. Aspects of the way each of the story elements of setting, plot and character were managed had important effects on the role play's overall effectiveness.

Although the pre-residential online activity was hampered by technical and communication difficulties, it still made a useful contribution in helping participants understand the complex nature of the setting and start to commit to their group and character role before the residential started. This enabled the face to face component of the role play to start with a strong level of energy and interest. The subsequent residential component was able to support intense engagement in the activity, which helped participants to not only involve themselves deeply in the make believe world, roles and events, but also have the time and space to reflect on the personal significance of what happened there.

Key aspects of the way the story elements were managed in the design and facilitation of the role play were as follows: 
- The story setting, based on two real organisations that happened to be of topical interest, was well chosen, well supported with rich information and props, and well understood by participants. It provided an interesting, realistic, relevant and challenging imaginary world in which participants could suspend disbelief and 'play' safely, and yet draw clear parallels to real management situations.

- The role play story plot developed engaging levels of conflict, complication and suspense. The expectation failure participants experienced at the climax and afterwards provided them with a strong stimulus to reflect on what a situation of organisational chaos had to teach them.

- An important effect of the participants' adoption of character roles as members of one or other of the highly competitive CFA or MFB groups was to intensify most participants' emotional and intellectual engagement in the activity. It is evident also that participants' experience of powerlessness, either as a result of being placed in a minor role or because of confusion about why one group had been judged harshly and whether the role play had ended or not, gave them valuable insights into how they and others tended to respond to uncomfortable, unpredictable and ambiguous situations. However, there was some boredom as some roles were not fully occupied at times.

The facilitators' capacity to construct and maintain the dramatic uncertainty to promote the desired learning for this role play was a key factor in its effectiveness as a learning and teaching technique. Individual teachers and facilitators would need to make the decision, based on their own teaching styles, capacities and preferences, as to whether to engage in the kind of 'risky business' the case study facilitators set up. The skills and capacities facilitators bring to an activity such as this need to include the provision of strategies and safety nets to help students manage the discomfort this experience can produce.

While the case study has provided insights into the effects of managing the story elements in a learning and teaching technique in a particular way, it is not possible to establish clear principles for how participative story formats should be designed and managed to enhance learning from the findings of this case study alone. The nature of people's engagement in stories and its link to learning is complex and requires ongoing research.

\section{Acknowledgments}

I wish to acknowledge with thanks the support and cooperation of John McWilliams, Ruby Ma and the student participants in the role play in this research and the publication of this paper. My thanks also to Catherine Beavis for her continued support.

\section{References}

Archambault, R. D. (Ed.) (1964). John Dewey on education: Selected writings. Random House, NY.

Baldick, C. (1990). The concise Oxford dictionary of literary terms. Oxford University Press, Oxford.

Bolton, G. \& Heathcote, D. (1999). So you want to use role play? Trentham, London. 
Carroll, J. (2002). Digital drama: a snapshot of evolving forms. Melbourne Studies in Education, $43(2), 130-141$.

Carroll, J., Anderson, M. \& Cameron, D. (2006). Real players? Drama, technology and education. Trentham, London.

Coleridge, S. T. (2004) (originally published 1817). Biographia Literaria. Project Gutenberg http:/ / www.gutenberg.org/ etext/ 6081 [viewed 27 June 2007]

Egan, K. (1997). The educated mind: How cognitive tools shape our understanding, University of Chicago Press, Chicago.

Freebody, P. (2003). Qualitative research in education: Interaction and practice. Sage, Thousand Oaks, CA.

Gee, J. P. (2003). What video games have to teach us about learning and literacy. New York, Palgrave Macmillan.

Gillham, B. (2000). Case study research methods. Continuum, London.

Graesser, A. C., Olde, B. \& Klettke, B. (2002). How does the mind construct and represent stories? In M. Green, J. Strange \& T. Brock (Eds), Narrative impact: Social and cognitive foundations. Lawrence Erlbaum Associates, Mahwah NJ.

Halliwell, S. (Ed \& trans) (1995). Extracts from Poetics 6-11. In M. Bal (2004), Narrative theory. Routledge, New York, pp. 59-64.

Harre, R. (1990). Some narrative conventions of scientific discourse. In C. Nash (Ed), Narrative in culture: The uses of storytelling in the sciences, philosophy, and literature. Routledge, London, pp. 81-101.

Knobel, M. \& Lankshear, C. (1999). Ways of knowing: Researching literacy. Primary English Teaching Association, Newtown NSW.

Kolb, D. (1984). Experiential learning: Experience as the source of learning and development. Prentice Hall, Engelwood Cliffs NJ.

Laurel, B. (1991). Computers as theatre. Reading, MA, Addison Wesley.

Malone, T. (1981). Toward a theory of intrinsically motivating instruction. Cognitive Science, 5(4), $333-69$.

McClusky, D. (1990). Storytelling in economics. In C. Nash (Ed), Narrative in culture: The uses of storytelling in the sciences, philosophy, and literature, Routledge, London, pp. 5-22.

McEwan, H. \& Egan, K. (Eds) (1995). Narrative in teaching, learning and research. Teachers College Press, Columbia University, New York.

Misson, R. \& Morgan, W. (2006). Critical literacy and the aesthetic: Transforming the English classroom. National Council of Teachers of English, Urbana, Illinois.

Murray, J. (1997). Hamlet on the holodeck: The future of narrative in cyberspace. The Free Press, New York.

Nell, V. (2002). Mythic structures in narrative. In M. C. Green, J. J. Strange \& T. C. Brock (Eds), Narrative impact: Social and cognitive foundations. Laurence Erlbaum, NJ, pp. 17-37. 
O'Toole, J. (2002). Drama: The productive pedagogy. Melbourne Studies in Education, 43(2), 39-52.

Prensky, M. (2001). Digital natives, digital immigrants. On the Horizon, 9(5). [verified 14 May 2008] http: / / www.marcprensky.com/writing/Prensky\%20-

$\%$ 20Digital\%20Natives, \%20Digital\%20Immigrants\%20-\%20Part1.pdf

Prensky, M. (2006). Don't bother me Mom-I'm learning. Paragon House, St Paul, Minnesota.

Raphael, J. \& O'Mara, J. (2002). A challenge, a threat and a promise: Drama as PD for teacher educators. Melbourne Studies in Education, 43(2), 77-87.

Ryan, M. L. (2001). Narrative as virtual reality: Immersion and interactivity in literature and electronic media. Johns Hopkins University Press, Baltimore.

Simons, J. (2002). Drama and the learner. Melbourne Studies in Education, 43(2), 1-11.

Strauss, A. \& Corbin, J. (1998). Basics of qualitative research: Techniques and procedures for developing grounded theory. Sage, Thousand Oaks, CA.

van Ments, M. (1999). The effective use of role-play: Practical techniques for improving learning, 2nd ed. Kogan Page, London.

Vygotsky, L. S. (1978). Mind and society: The development of higher mental processes. Harvard University Press, Cambridge, MA.

White, H. (1980). The value of narrativity in the representation of reality. Critical Inquiry, 7(1), 527.

Wills, S. \& Ip, A. (2002). enRole, research, read, resolve, reflect: Developing and using online role play learning designs. Learning Designs, University of Wollongong [viewed 3 Mar 2008] http: / / www.learningdesigns.uow.edu.au/guides/info/G1/index.htm

Wills, S., Ip, A. \& Bunnett, A. (2000). Complementary pedagogical strategies for online design. In Learning to choose-choosing to learn. Proceedings ASCILITE 2000, pp. 405-414.

http:/ / www.ascilite.org.au/conferences/ coffs00 / papers/sandra_wills.pdf

Yin, R. K. (2003). Case study research design and methods, 3rd edn, Sage, Thousand Oaks.

Mary Dracup, Teaching Support Consultant

Institute of Teaching and Learning

Waterfront Campus, Deakin University

Geelong Vic 3217

Australia.

Email: mary.dracup@deakin.edu.au 